\title{
O CORPO NA FORMAÇÃO INICIAL EM PEDAGOGIA: UMA ANÁLISE DOS CURRÍCULOS DAS UNIVERSIDADES FEDERAIS DO BRASIL
}

\author{
Carolina Barbosa da Silva \\ Universidade do Sul de Santa Catarina, Tubarão, Santa Catarina, Brasil. \\ Márcia Buss-Simão \\ Universidade Federal de Santa Catarina, Florianópolis, Santa Catarina, Brasil.
}

\begin{abstract}
Resumo
O presente artigo apresenta o resultado de uma pesquisa que objetivou investigar, nas bases curriculares dos cursos de Pedagogia das universidades federais do Brasil, o lugar do corpo na formação inicial e as concepções de corpo privilegiadas nos currículos dos cursos de Pedagogia. Como metodologia para reunir e organizar os dados, recorreu-se à Técnica de Análise de Conteúdo, utilizando palavras-chave como corpo, movimento e educação física a fim de localizar as disciplinas que tratassem da temática de pesquisa nos currículos dos cursos de Pedagogia. Esse processo resultou na definição do corpus desta pesquisa em cinco categorias de análise, considerando os limites de um artigo, são apresentados os dados e as análises referentes à categoria Educação do corpo.
\end{abstract}

Palavras-chave: Pedagogia. Currículo. Corpo.

\section{THE BODY IN THE INITIAL FORMATION IN PEDAGOGY: AN ANALYSIS OF THE CURRICULA OF THE FEDERAL UNIVERSITIES OF BRAZIL}

\begin{abstract}
The present article presents the results of a research that aimed to investigate, in the curricular bases of the courses of Pedagogy of the Federal Universities of Brazil, the place of the body in the initial formation and the privileged body conceptions in the curricula of the Pedagogy courses. As a methodology to gather and organize data, we used the Content Analysis Technique, using keywords such as body, movement and physical education in order to locate the disciplines that deal with the research topic in the curricula of the Pedagogy courses. This process resulted in the definition of the corpus of analysis in five categories of analysis, considering the limits of an article, the data and analyzes referring to the category of Education of the body are presented.
\end{abstract}

Keywords: Pedagogy. Curriculum. Body.

\section{EL CUERPO EN LA EDUCACIÓN INICIAL EN PEDAGOGÍA: UN ANÁLISIS DE CURRÍCULOS EN LAS UNIVERSIDADES FEDERALES DE BRASIL}

\section{Resumen}

El presente artículo presenta el resultado de una investigación, que objetivó investigar en las bases curriculares de los cursos de Pedagogía de las Universidades Federales de Brasil, el lugar del cuerpo en la formación inicial y las concepciones de cuerpo privilegiadas en los currículos de los cursos de Pedagogía. Como metodología para reunir y organizar los datos, se 
recurrió a la Técnica de Análisis de Contenidos, utilizando palabras clave como cuerpo, movimiento y educación física a fin de localizar las disciplinas que tratase de la temática de investigación en los currículos de los cursos de Pedagogía. Este proceso resultó en la definición del corpus de análisis en cinco categorías de análisis, considerando los límites de un artículo, se presentan los datos y los análisis referentes a la categoría Educación del cuerpo.

Palabrasclave: Pedagogía. Currículos. Cuerpo.

\section{Contextualizando a pesquisa}

O presente artigo é resultado da pesquisa de mestrado de Barbosa (2015), em que buscamos analisar, nas bases curriculares dos cursos de Pedagogia das universidades federais do Brasil, qual o lugar do corpo na formação inicial e as concepções de corpo privilegiadas nos currículos dos cursos de Pedagogia. Consideramos os cursos de Pedagogia como contexto importante de formação dos profissionais que vão atuar na Educação Infantil e nos anos iniciais do Ensino Fundamental, ou seja, os profissionais que atuarão com crianças de 0 a 10 anos, contribuindo significativamente na constituição e na construção social e cultural do corpo por meio das práticas educativas. As reflexões de Vaz (2002), ao tratar da formação inicial da Pedagogia e da Educação Física, reforçam essa compreensão, pois o autor destaca a necessidade em buscar interconexões entre as áreas:

\footnotetext{
Diz-se, por exemplo, que a Educação Física "trabalha o corpo", o que é verdade. Acontece, porém, que ela reúne apenas uma parte, seguramente importante, das técnicas corporais e dos cuidados com o corpo em ambientes educacionais. Essas técnicas e cuidados estão presentes em muitos outros momentos do cotidiano escolar, dos hábitos de higiene aos alimentares, dos imperativos disciplinares aos castigos, do espelho de classe aos preconceitos, dos ideais de beleza aos interditos de gênero. Quando os/as alunos/as estão com a "professora de sala", não se alheiam de seus corpos, que são alvo, no entanto, de processos de disciplinamento e contenção das crianças. Crianças que ficam em suas cadeiras estão tendo seus corpos educados; quando podem ou não andar/correr pelos corredores, ou mesmo entre as carteiras e mesinhas, também. (VAZ, 2002, p.138, grifo do autor).
}

Nesse sentido, consideramos relevante conhecer como a temática do corpo tem sido apresentada nos currículos do curso de Pedagogia, considerando que esses profissionais estarão com as crianças exercendo docência na Educação Infantil e nos anos iniciais do Ensino Fundamental. Portanto, a formação inicial em Pedagogia deveria trazer elementos para esses profissionais compreenderem o corpo como componente dos processos educativos. Com base em Le Breton (2006), partimos de uma concepção de corpo como fenômeno social e cultural. Nessa concepção, as ações que tecem a trama da vida cotidiana, desde as mais simples e menos concretas até aquelas que ocorrem na cena pública, sempre envolvem a mediação do corpo, as quais devem ser consideradas na ação educativa.

As creches, pré-escolas e escolas, por serem instituições sociais, possuem uma relação dialética com a sociedade em que estão inseridas, em que existem, de um lado, as práticas educativas que são influenciadas e determinadas pela cultura e pelo sistema dominante da moderna sociedade capitalista e, do outro, as lutas por transformações sociais. Foucault (2012) refere, por exemplo, que, por meio da imposição dos horários, estabelecidos pelas instituições, é possível controlar as obrigações, determinações e regulamentações, procurando tornar o tempo útil e de boa qualidade. Também nessa crítica podemos mencionar a contribuição de Soares (2001, p. 112), ao citar que "as pedagogias são portadoras de preceitos que dão aos corpos uma forma e os esquadrinham para submetê-los a normas, seguramente mais ainda 
que o pensamento". Essas influências induzem gestos, posturas, comportamentos e regras determinadas por uma ordem social que afeta os corpos e constrói o seu modo de ser e de se expressar. Isso é complementado por Soares (2001, p. 110), ao afirmar que "os corpos são educados por toda realidade que os circunda, por todas as coisas com as quais convivem, pelas relações que se estabelecem em espaços definidos e delimitados por atos de conhecimento".

Historicamente, a educação do corpo é destaque, como elucidam Soares e Fraga (2003), em que o objetivo de conhecê-lo, em várias áreas, como a medicina, o jurídico, o pedagógico e o literário visa conhecer para dominar. Compreendemos que a constituição e a construção do corpo se dão numa contínua interação entre homem e mundo, por meio de práticas socioculturais que serão marcadas nesse corpo por meio das diferentes experiências vivenciadas. Santos (1999) corrobora com essa discussão quando afirma que somos e temos um corpo, sendo impossível separá-los, e a construção desse corpo se dá também nos espaços e relações educativas. Santos (1999) também cita que o corpo faz parte do processo educacional e, por conseguinte, deve estar inserido no currículo; além disso, enfatiza que "a moldagem dos corpos e seu disciplinamento não são apenas um dos componentes centrais do currículo, mas, provavelmente, um de seus efeitos duradouros e permanentes que torna controláveis corpos incontrolados" (1999, p. 195). Santos (1999, p. 205) argumenta que:

A escola e o currículo, como dimensões organizadas, legitimadas e comprometidas com as transformações sociais, precisam incorporar outras representações culturais, além da biomédica, discutindo como o corpo, superfície de inscrição das marcas de seu tempo, conta as histórias que nele se inscrevem. Em outras palavras, [...] enfatizar que o conhecimento científico, por si só, não basta.

É preciso identificar que o conhecimento materializado no currículo não é algo fixo, mas submetido a um processo em constante evolução e que sofre interferência da construção social determinada pelo momento histórico, pelas crenças, expectativas e visões de mundo. Segundo Goodson (2012, p. 10), "o currículo deve ser visto não apenas como a expressão ou a representação ou o reflexo de interesses sociais determinados, mas também como produzindo identidades e subjetividades sociais determinadas", portanto, as presenças e a ausências das discussões do corpo, na formação inicial em Pedagogia, contribui na determinação da produção dessa dimensão nos contextos educativos. Como indica Le Breton (2009), variadas experiências sociais e culturais têm o poder de congregar aos corpos diferentes marcas que se modificam durante os processos educativos presentes nas creches, pré-escolas e escolas.

Os currículos, para Silva $(2012$, p. 8) não devem ser interpretados "como resultado de um processo social necessário de transmissão de valores, conhecimentos e habilidades, em torno dos quais haja um acordo geral, mas como um processo constituído de conflitos e lutas entre diferentes tradições e diferentes concepções sociais". Nesse sentido, ao buscar as presenças e ausências do corpo nos currículos dos Cursos de Pedagogia, partimos da compreensão, como indica Gimeno Sacristán (2013, p. 23) de que o currículo: "Não é algo neutro, universal e móvel, mas um território controverso a respeito do qual se tomam decisões, são feitas opções e se age de acordo com orientações que não são as únicas possíveis".

Partir dessa concepção de currículo implica reconhecer que a seleção e a organização que reverberam nas presenças e ausências de determinados conhecimentos nos currículos não são, de modo algum, desinteressados. Pelo contrário, revelam sempre disputas epistemológicas, teóricas e culturais de concepção de educação, de homem e de sociedade. Nesse sentido, interessa trazer nesse texto, particularmente, uma análise dos currículos dos cursos de Pedagogia, sendo que a Resolução CNE/CP n. 1, de 15 de maio de 2006, que instituiu as Diretrizes Curriculares Nacionais para o curso de graduação em Pedagogia licenciatura (DCNCP/2006) que trazem uma nova configuração curricular para essa área, ao instituírem a formação inicial 
para o exercício da docência na educação infantil e não apenas para os anos iniciais do ensino fundamental.

\section{Caminhos metodológicos}

Para o levantamento dos dados nos currículos dos cursos de Pedagogia, utilizamos o banco de dados em formato eletrônico elaborado por Albuquerque (2013) em sua tese de doutorado. Para a seleção do material desse banco de dados, Albuquerque (2013) privilegiou somente os conteúdos dos currículos pós DCNCP/2005 e Resolução n ${ }^{\circ} 1 / 2006$, pois a partir dessa Resolução, as orientações para os cursos de Pedagogia passaram a ter como eixo central uma formação para a docência da Educação Infantil e Ensino Fundamental, articulada e indissociável com a gestão e a pesquisa. Segundo a pesquisa de Albuquerque (2013), existiam 57 universidades cadastradas, sendo que 47 delas ofereciam o curso de Pedagogia. Destas, somente constam no banco de dados da autora as universidades que enviaram a matriz curricular dos cursos de Pedagogia e de outras que foram recolhidas por meios de seus endereços eletrônicos, contabilizando um total de 33 matrizes curriculares. Cabe ainda destacar que foram incluídas no banco somente as disciplinas obrigatórias, pois estas serão cursadas por todos/as os/as estudantes matriculados/as, já as eletivas dependem tanto da possibilidade da oferta como de adesão de cada um, não fazendo, portanto, parte da formação inicial de todos/as.

Para a geração dos relatórios de busca das disciplinas, utilizamos as palavras-chave: corpo, movimento e educação física. A escolha dessas palavras-chave seguiu o critério de contemplar temáticas privilegiadas pelo campo da Educação Física que mantém uma aproximação semântica com o corpo ${ }^{1}$. Essa primeira busca, com as três palavras-chave definidas, resultou em três relatórios, um composto de 39 disciplinas na categoria corpo, outro com 28 na categoria educação física e um terceiro com 52 na categoria movimento. Realizamos uma leitura minuciosa dos títulos das disciplinas e suas respectivas ementas, após a leitura desses primeiros relatórios, observamos que muitas disciplinas com a palavra corpo, na verdade, não tratavam do tema de nossa pesquisa e, sim, de outras temáticas como história, matemática, política, gestão escolar, valores estéticos e culturais e metodologia científica. Observamos, também, que as disciplinas resultantes da busca com a palavra movimento, geradas nessa primeira procura, não se relacionavam com o tema da pesquisa, mas sim com temas como: movimentos sociais, movimento indígena, movimento de educação popular e movimento da imagem. Também com a palavra educação física algumas disciplinas não se relacionavam ao tema, tinham uma abordagem mais histórica e conceitual do desenvolvimento das crianças voltado para a qualificação do trabalho pedagógico. Por esse motivo, essas disciplinas que não tinham relação com o tema foram descartadas.

Nesse processo, foi preciso uma leitura mais atenta das ementas, que culminou numa nova seleção. Ao final dessa busca, realizamos um cruzamento entre os três relatórios a fim de ainda excluir as disciplinas que se repetiam nas buscas com as palavras-chave, optando sempre por selecioná-la uma única vez. Após esse cruzamento, restaram nos três relatórios, os seguintes números de disciplinas: 25 com a palavra corpo, $1 \mathrm{com}$ a palavra movimento e 1 com educação física, totalizando um número de 27 disciplinas que compuseram nosso corpus de análise.

Para essa organização dos dados, utilizamos como estratégia metodológica a Técnica de Análise de Conteúdo de Bardin (2011), e seguindo o critério da homogeneidade dos documentos, optamos por não analisar as referências bibliográficas e nem os planos de ensino,

1 Numa primeira busca ao banco de dados de Albuquerque (2013), utilizamos as palavras gênero e relações de gênero, porém as disciplinas se repetiram nas outras buscas, em particular nas buscas com o termo corpo. 
visto que somente algumas universidades disponibilizavam essa informação e a grande maioria das disciplinas do banco de dados de Albuquerque (2013) não as incluíam.

Para as análises dos dados que constituíram nosso corpus de pesquisa, buscamos definir algumas categorias de análise por meio de cruzamentos dos títulos das disciplinas com os conteúdos das ementas, o que resultou em cinco categorias, das quais na categoria definida como Educação do corpo, em que o corpo é o tema central da disciplina, foram agrupadas 10 disciplinas. A categoria definida como Educação do corpo de modo indireto, na qual o corpo se entrelaça com um conjunto de outros saberes e o tema corpo não aparece no nome da disciplina, somente na ementa, contabilizou cinco disciplinas. A categoria $O$ corpo nos jogos, na arte e no lúdico, que tem uma abordagem do corpo associada aos jogos, ludicidade e arte, foi encontrada em cinco disciplinas. A definição da categoria Corpo como biológico e natural, que trata o corpo a partir características biológicas e psicológicas, contabilizou 5 disciplinas. Somente 2 disciplinas apresentaram o corpo como forma de comunicação e expressão corporal e facial, denominadas de $O$ corpo na comunicação em LIBRAS. Procurando visualizar os dados, organizamos o Gráfico 1:

Gráfico 1 - Disciplinas com o tema corpo nos cursos de Pedagogia agrupadas por categorias

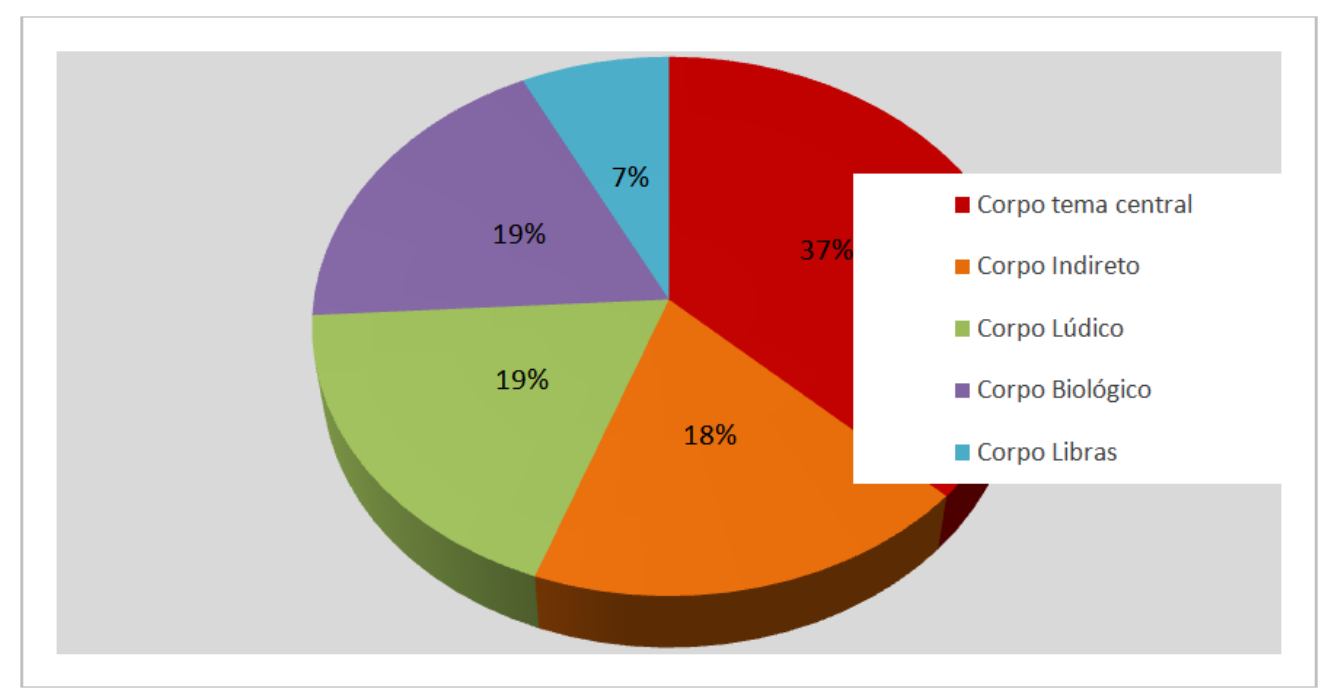

Fonte: Elaborado pelas autoras com base em Barbosa (2015).

Ao observar o Gráfico 1, podemos evidenciar que a categoria Educação do corpo, em que o corpo é o tema central da disciplina e a categoria definida como Educação do corpo de modo indireto, que discute o corpo no conjunto de outros saberes, compõe um conjunto de mais da metade das 27 disciplinas encontradas nos cursos de Pedagogia das universidades federais. Mesmo sendo esse número relativamente pequeno, comparado à quantidade total de horas de formação nos currículos e, mesmo a ausência dessas temáticas na grande maioria das matrizes curriculares dos cursos de Pedagogia, mostra, todavia, uma presença nas universidades que possuem disciplinas com o tema corpo nos cursos de graduação dos/as professores/as de Educação Infantil e anos iniciais do Ensino Fundamental.

Agrupando essas categorias por regiões no Brasil, chegamos também a alguns dados que reafirmam a disparidade regional, característica histórica no Brasil, aqui mais especificamente no que se refere a quantidade de universidades que apresentam disciplinas com o tema corpo como eixo central, como podemos observar no Quadro 1: 
Quadro 1 - Disciplinas do curso de Pedagogia das universidades federais com o tema corpo, por região

\begin{tabular}{|c|c|c|c|c|c|}
\hline Região & $\begin{array}{c}\text { Corpo tema } \\
\text { central }\end{array}$ & $\begin{array}{c}\text { Corpo tema } \\
\text { indireto } \\
\end{array}$ & $\begin{array}{l}\text { Corpo } \\
\text { lúdico } \\
\end{array}$ & $\begin{array}{c}\text { Corpo biológi- } \\
\text { co } \\
\end{array}$ & $\begin{array}{c}\text { Corpo comu- } \\
\text { nicação } \\
\end{array}$ \\
\hline Norte & 1 & 0 & 1 & 1 & 0 \\
\hline Nordeste & 1 & 3 & 0 & 2 & 1 \\
\hline Centro-oeste & 0 & 0 & 1 & 0 & 0 \\
\hline Sudeste & 5 & 2 & 2 & 1 & 1 \\
\hline Sul & 3 & 0 & 1 & 1 & 0 \\
\hline TOTAL & 10 & 5 & 5 & 5 & 2 \\
\hline
\end{tabular}

Fonte: Elaborado pelas autoras com base em Barbosa (2015).

Um dado interessante nessa distribuição, em particular com relação a categoria que tem o corpo como tema central, é que mesmo que essas disciplinas, com esse tema, estejam presentes no Norte, na Universidade Federal do Amapá (UNIFAP), e Nordeste, na Universidade Federal de Alagoas (UFAL), elas se concentram mais nas regiões Sudeste, na Universidade Federal do Espírito Santo (UFES), Universidade Federal de São Carlos (UFSCar), Universidade Federal do Rio de Janeiro (UFRJ), Universidade Federal do Estado do Rio de Janeiro (UNIRIO) e Universidade Federal de Minas Gerais (UFMG), e Sul, na Universidade Federal da Fronteira do Sul (UFFS), Universidade Federal de Santa Catarina (UFSC) e Universidade Federal do Pampa (UNIPAMPA), demonstrando ser mais forte a presença do corpo nas disciplinas do curso de Pedagogia dessas regiões. É provável que esse dado esteja relacionado ao fato de a maior concentração de universidades e de programas de pós-graduação, segundo Ramalho e Madeira (2005), estarem nas regiões Sudeste e Sul, e talvez pela longevidade, ou seja, uma constituição mais antiga dessas universidades permita que as mesmas compreendam que o corpo é um conteúdo importante para ser discutido nos cursos de Pedagogia. Outra hipótese seria a presença de professores/as e pesquisadores/as nessas universidades que consideram que a discussão sobre o corpo seja importante no curso de Pedagogia e, por conta desse posicionamento, tais universidades possuam disciplinas que apresentam discussões que privilegiam esse tema. No entanto, não há como comprovar esse fato nesta pesquisa, mas isso mostra que as universidades federais não seguem um padrão de temas e ementas nas disciplinas ofertadas nos cursos de Pedagogia.

Na sequência, considerando os limites de um artigo, apresentaremos dados referentes a categoria que teve o corpo como tema central nas disciplinas localizadas no banco de dados, procurando evidenciar as concepções de corpo a partir das análises dos títulos e das ementas das disciplinas localizadas nos currículos dos cursos de Pedagogia.

\section{O corpo nos currículos de pedagogia}

Pensar o corpo na formação inicial em Pedagogia e nas creches, pré-escolas e escolas é, primeiramente, compreender que ele não é unicamente um instrumento das práticas educativas, mas também produções humanas baseadas no corpo como princípio epistemológico, com possibilidade de contribuir na construção do conhecimento e nas experiências sociais e culturais. Segundo Nóbrega (2005, p. 610), "a gestualidade ou os cuidados com o corpo podem e devem ser tematizados nas diversas práticas educativas propostas nos currículos e viabilizados por diferentes disciplinas". Porém, para tal, é preciso que os/as professores/as ampliem a concepção instrumental de corpo e compreendam que abordar aspectos da dimensão corporal vai além dos métodos gímnicos e/ou do movimento gestual caracterizado por jogos e 
brincadeiras. Nesse sentido, Nóbrega (2005) afirma que somos seres corporais, portanto, o corpo já está incluído na educação.

A seleção das disciplinas que compõem a categoria denominada Educação do corpo teve como critério de agrupamento aquelas que tratassem de forma central e específica do corpo. Quase todas as disciplinas agrupadas nessa categoria continham o termo corpo no título, posteriormente, seguindo o processo de categorização de Bardin (2011), realizamos uma leitura minuciosa das ementas e percebemos que outra disciplina, mesmo sem conter o termo corpo no seu título, tinha na ementa assuntos relacionados diretamente ao corpo, sendo este o tema central dessa disciplina.

Agrupamos nessa categoria 10 disciplinas, ou seja, 37\% do total selecionado na pesquisa, cujas discussões estão centradas especificamente na temática do corpo. Cabe dar destaque que, mesmo tendo o corpo como central, as disciplinas têm base em diferentes concepções: estudos teóricos e práticos da corporeidade; corpo e movimento; vivência do movimentar-se tanto no contexto educativo quanto na sociedade; consciência corporal e relação do corpo com o outro. Numa análise geral, é possível identificar que as ementas valorizam o corpo tanto na dimensão do movimento quanto nas experiências sociais e culturais como construção da infância.

Para a análise do conjunto de disciplinas que compõem essa categoria, denominada Educação do corpo, realizamos um agrupamento por temáticas que se repetiam para melhor identificar as concepções de corpo presentes nas 10 disciplinas $^{2}$. Esse agrupamento resultou em dois conjuntos de disciplinas: um traz o corpo numa concepção de movimento e, o outro, o corpo na concepção da expressividade, da linguagem corporal e da cultura. Isso demonstra que essas 10 disciplinas não possuem somente uma única concepção de corpo, como, por exemplo, a disciplina Linguagem Corporal na Educação, da UFRJ e na disciplina Corpo $e$ Movimento na UNIRIO e na UFFS, que em suas ementas - que são idênticas - apresentam: "Aspectos históricos, antropológicos e culturais. Corpo, disciplina, gênero e sexualidade. $\mathrm{O}$ corpo e a relação com o outro. Consciência corporal e identidade. O direito de movimentar-se. O movimento como recurso de prazer, educação e saúde".

A temática que mais apareceu nas disciplinas dessa categoria foi a do corpo na concepção do movimento. A discussão dessa temática é importante para a formação dos/as pedagogos/as, pois possibilita uma compreensão da necessidade e relevância de proporcionar situações e experiências com o corpo e o movimento que permitam às crianças compreenderem significações culturais e sociais presentes nessas experiências. É o caso da disciplina Corporeidade e Movimento, da UFAL, que apresenta na ementa: "Estudo teórico-prático do fenômeno da corporeidade e a experiência fenomenológica do corpo em movimento a partir da experiência vivida compreendendo o corpo como modo de ser no mundo"; da disciplina Corpo e Movimento da UFSCar, que em parte de sua ementa apresenta: "O eixo condutor desta disciplina será a discussão sobre as diferentes concepções de corpo e de movimento desenvolvidas ao longo da história da humanidade [...] bem como as formas de superação de concepções biologicistas [...] o aprofundamento da consciência sobre a imprescindibilidade do trabalho com movimento no incremento da qualidade dos processos de ensino e aprendizagem"; assim como da disciplina Corpo e Educação, da UFMG, que em parte de sua ementa aborda: "[...] O corpo e o movimento nas diversas áreas de atuação do pedagogo".

Uma formação inicial em Pedagogia, que traga para o centro da discussão essa concepção de corpo, é fundamental para romper, como indica Sayão (2002), com a falta de conhecimentos da importância do corpo para além de estar a serviço das aprendizagens cognitivas ou do esporte de rendimento:

2 As universidades que ofertam essas disciplinas são: UFAL; UFES; UFSCar; UNIPAMPA; UFRJ; UFSC; UNIFAP; UNIRIO; UFMG e UFFS. 
A escuta das futuras pedagogas dos/as acadêmicos/as da educação física, assim como de profissionais já atuantes no magistério, demonstra as "faltas" decorrentes de seu processo de formação que se evidenciam numa certa "incapacidade" momentânea de perceberem a brincadeira, o jogo e o movimento corporal das crianças para além do aspecto funcional de contribuição para a melhoria das aprendizagens cognitivas ou dos esportes de rendimento. (SAYÃO, 2002, p. 58).

Por conta disso, é importante o conhecimento da temática do corpo na concepção do movimento para a formação inicial dos/as pedagogos/as, visto que este pode fornecer indicações para as práticas docentes e efetivação de uma docência que não compreenda o corpo somente do ponto de vista da contenção dos movimentos e ações das crianças visando a aquisição de conhecimentos cognitivos. Uma aproximação com essa concepção é encontrada nas Diretrizes Curriculares Nacionais para Educação Infantil (DCNEI) que é um documento de caráter mandatório na área, o qual indica que as práticas pedagógicas que compõem a proposta curricular da Educação Infantil devem promover, segundo o Art. $9^{\circ}$ inciso I: "o conhecimento de si e do mundo por meio da ampliação de experiências sensoriais, expressivas, corporais que possibilitem movimentação ampla" (BRASIL, 2009).

Outra temática de corpo que apareceu nessa categoria, resultando num segundo conjunto de análise, foram disciplinas que discutem o corpo como linguagem, expressividade e cultura, a exemplo da disciplina Corporeidade e Educação na UNIPAMPA, que em parte de sua ementa, apresenta: "Fundamentos teórico-práticos de procedimentos mediadores na relação corporal com crianças de zero a seis anos e dos primeiros anos escolares com ênfase no uso de práticas lúdicas que contemplem a expressividade, a afetividade, a inclusão e a imaginação [...]". Essa dimensão, que envolve o corpo, é também privilegiada nas DCNEI em seu Art. $9^{\circ}$, nos incisos II e IX, indicando a importância da proposta curricular da Educação Infantil favorecer a imersão das crianças nas diferentes linguagens e formas de expressão, promovendo "o relacionamento e a interação das crianças com diversificadas manifestações de música, artes plásticas e gráficas, [...] dança e teatro" (BRASIL, 2009). Essa compreensão de corpo pode ser observada também na disciplina Educação, Corpo e Movimento, da UFES, quando privilegia na ementa reflexões sobre "[...] sentidos e significados da corporeidade como linguagem corporal e como construção da infância".

Essa concepção de corpo como linguagem, expressividade e cultura também está presente nas disciplinas Linguagem Corporal na Educação, da UFRJ, e Corpo e Movimento, da UNIRIO e da UFFS, que abordam na ementa "aspectos históricos, antropológicos e culturais. Corpo, disciplina. [...] O corpo e a relação com o outro. Consciência corporal e identidade". Consideramos essas discussões essenciais na formação inicial em Pedagogia, visto que a educação do corpo, como lembra Soares (2001), envolve diversos processos culturais que, com o passar dos tempos, adquirem novos rumos, interesses e relações.

As crianças apropriam-se das experiências sociais e culturais com o corpo e compartilham a sua interpretação com outras pessoas; nesse processo de construção dos saberes e de constituição social de sua própria infância, o corpo ocupa um lugar central. Como indica Sayão (2002, p. 57), em contextos educativos:

[...] talvez um passo necessário seja reconhecermos que as interações entre crianças e adultos acontecem por intermédio de seus corpos que estão situados em um contexto sociocultural. Esse contexto vai determinando modos de ser, exige-lhes performances, ou seja, os corpos de adultos e crianças estão imersos em uma determinada cultura. Olhares, gestos, expressões, falas, representações são manifestações típicas das diferentes culturas que, quando manifestadas, são comunicadas e compreendidas por intermédio de códigos e/ou signos. 
Numa análise geral dessa categoria denominada por nós de Educação do corpo, é possível constatar que existem diferentes concepções de corpo nas disciplinas dessa categoria, pois algumas discutem a temática corpo na perspectiva de movimento e outras do ponto de vista da expressividade, da linguagem e da cultura. Essas concepções são imprescindíveis na construção das experiências pedagógicas que os/as futuros/as pedagogos/as necessitam, visto que a ação pedagógica deve ser conduzida de modo a ampliar e diversificar as linguagens expressivas das crianças, além de levar em conta as linguagens que elas utilizam para se expressarem e se comunicarem. A ementa da disciplina Corpo e Educação da UFMG, "O corpo e a escola: intervenções históricas e atuais de controle e castigo. Possibilidades de construção de conhecimento por meio do corpo", também traz elementos para problematizar o corpo nos contextos educativos, pois é urgente que pedagogos/as concebam as crianças e o corpo para além de sua contenção e disciplinamento e, mais, que vislumbrem possibilidades de construção de conhecimento por meio do corpo.

Outro dado relevante, observado nesse conjunto de disciplinas, é que elas não evidenciam tratar de assuntos centrados nos moldes do Ensino Fundamental, visto que nas ementas não constam tópicos sobre material didático, diretrizes ou parâmetros curriculares, temas correspondentes a essa etapa educativa. Por outro lado, parecem ser disciplinas direcionadas à docência na Educação Infantil e, em alguns casos, também aos anos iniciais do Ensino Fundamental, sob a ótica de compreensão da infância de modo mais alargado, assim como indicam os estudos e pesquisas que buscam contribuir para que haja uma continuidade na transição dessas duas etapas educativas. Essa perspectiva pode ser observada na disciplina Corpo $e$ Movimento da UFSCar, cuja ementa registra que "o foco das discussões será a qualidade das mediações desenvolvidas por professores em atividades realizadas com as crianças de 0 a 10 anos", na disciplina Corporeidade e Educação da UNIPAMPA, cuja ementa traz os "fundamentos teórico-práticos de procedimentos mediadores na relação corporal com crianças de zero a seis anos e dos primeiros anos escolares", além das disciplinas Educação, Corpo e Movimento, da UFES, e Infância e Educação do Corpo, da UFSC, que apresentam discussões direcionadas para a infância.

Entretanto, mesmo havendo evidências nas ementas de que há uma centralidade da discussão para a docência na área da Educação Infantil, compreendemos que o corpo ainda não é contemplado de modo suficiente, pois nessa etapa educativa, o corpo ocupa grande centralidade nas ações pedagógicas, tanto no que se refere às ações pedagógicas de cuidados corporais, nas relações de gênero e sexualidade, como nas experiências com o movimento e com o corpo expressivo.

Quando voltado para o Ensino Fundamental, há evidências de que esse corpo seja valorizado numa perspectiva de contenção do mesmo, como forma de melhor apropriação dos conteúdos estudados nessa etapa educativa. Desse modo, o corpo ganha lugar e espaço quando está fora de sala, mas mesmo assim de maneiras restritas, sendo mais comum nas atividades da Educação Física por meio do esporte e das práticas de jogos competitivos e coletivos. Não compartilhamos dessa concepção hegemônica presente na educação, por isso, consideramos importante que os/as professores/as valorizem o corpo, em todas as suas dimensões, também no Ensino Fundamental.

\section{Considerações finais}

O recorte da pesquisa de Barbosa (2015), aqui apresentado, possibilita evidenciar que a temática do corpo está presente em 27 disciplinas nos currículos dos cursos de Pedagogia em 18 universidades federais no Brasil. Essa quantidade de universidades que apresentam disciplinas com discussões sobre o tema corpo não é significativa, se comparada às 33 universidades, que compõe o banco de dados, que ofertam formação em cursos de Pedagogia nas 
cinco regiões brasileiras. Esses números revelam também o quanto a discussão sobre o corpo ainda não abrange grande parte das universidades brasileiras.

No processo de análise, foi possível constatar que as disciplinas que abordam a temática do corpo trazem estudos teóricos e práticos da corporeidade; estudos sobre corpo e movimento; sobre vivência do movimentar-se tanto no contexto educativo quanto na sociedade; consciência corporal e relação do corpo com o outro. De modo geral, é possível identificar que as ementas valorizam o corpo tanto na dimensão do movimento quanto nas experiências sociais e culturais como a construção da infância. Também foi possível perceber que essas disciplinas são mais evidenciadas na formação para a docência na Educação infantil, desaparecendo gradativamente no currículo dos cursos de Pedagogia nas disciplinas que contribuem com a formação específica da docência para o Ensino Fundamental.

A pesquisa traz como indicativo a necessidade de os cursos de Pedagogia valorizarem mais as discussões sobre o corpo nas suas diversas dimensões, pois partimos da compreensão de que essa discussão acerca do corpo, durante a formação inicial de Pedagogia, contribui também para que as/os profissionais compreendam seus próprios corpos, ampliando sua sensibilidade para essa dimensão, o que pode contribuir e trazer indicativos para suas ações docentes e de sua importância para a compreensão dos processos educativos.

A materialidade inegável do corpo sempre o tornou central nos processos educativos, todavia, é preciso discussões que invertam, ou talvez subvertam o modo como ele tradicionalmente foi compreendido, ou seja, como meio de submissão, controle ou recurso pedagógico. Numa perspectiva de educação que visa a emancipação das crianças, o corpo continua sendo central, pois ele é base de toda experiência social, conforme indica Le Breton (2009).

Do ponto de vista de uma continuidade de estudos, assim como já mencionamos em Albuquerque, Rocha, Buss-Simão (2018), consideramos relevante estabelecer uma relação nas universidades federais estudadas das linhas e grupos de pesquisas presentes em cada universidade - de forma a identificar relações entre produção científica do campo e as implicações para os cursos de graduação, mesmo que limitadas à análise de suas estruturas curriculares. Consideramos uma atualização do banco de dados analisado de extrema relevância, tendo em conta que naquele momento, nos anos de 2010/2011, os currículos dos cursos de Pedagogia buscavam se adequar à implementação das Diretrizes Curriculares Nacionais para o curso de Pedagogia de 2006. Atualmente, é provável que novos cursos tenham sido criados e que os currículos dos cursos de Pedagogia tenham sofrido alterações, atualizações e consolidações decorridos 10 anos de implementação das Diretrizes Curriculares Nacionais para o curso de Pedagogia.

\section{Referências}

ALBUQUERQUE, M. H. K. Formação docente para educação infantil no Brasil: configurações curriculares nos cursos de Pedagogia. 2013. Tese (Doutorado em Educação) - Centro de Ciências da Educação, Universidade Federal de Santa Catarina, Florianópolis, 2013.

ALBUQUERQUE, M. H. de; ROCHA, Eloisa A. C.; BUSS-SIMÃO, M.. Formação docente para educação infantil nos currículos de pedagogia. Educação em Revista, Belo Horizonte, v. 34, p. 1-24, 2018.

BARBOSA, Carolina da Silva. A dimensão corporal na formação inicial de Pedagogia: uma análise dos currículos nas Universidades Federais do Brasil. 2015. 137 f. Dissertação (Mestrado em Educação) - Universidade do Sul de Santa Catarina, Tubarão, 2015. 
BRASIL. Conselho Nacional de Educação. Resolução CNE/CP $\mathbf{n}^{0}$ 1, de 15 de maio de 2006a. Institui Diretrizes Curriculares Nacionais para o Curso de Graduação em Pedagogia, licenciatura. Brasília: CNE. 2006a.

BRASIL. Conselho Nacional de Educação. Parecer CNE/CP no 3/2006b. Institui Diretrizes Curriculares Nacionais para o Curso de Pedagogia. Brasília: CNE, 21, fev. 2006b.

BRASIL. Ministério da Educação. Conselho Nacional de Educação. Câmara de Educação Básica. Resolução n $\mathbf{n}^{\mathbf{5}}$, de 17 de dezembro de 2009. Fixa as Diretrizes Curriculares Nacionais para a Educação Infantil. Brasília: CNE. 2009.

BARDIN, L. Análise de conteúdo. São Paulo: Edições 70, 2011.

FOUCAULT, M. Vigiar e punir: nascimento da prisão. Tradução Raquel Ramalhete. Petrópolis: Vozes, 2012.

GOODSON, I. Currículo: teoria e história. Petrópolis: Vozes, 2012.

LE BRETON, D. A Sociologia do Corpo. Petrópolis: Vozes, 2006.

LE BRETON, D. As paixões ordinárias: antropologia das emoções. Petrópolis: Vozes, 2009.

NÓBREGA, T. P. Qual o lugar do corpo na educação? Notas sobre conhecimento, processos cognitivos e currículo. Educação e Sociedade, Campinas, v. 26, n. 91, 599-615, maio/ago. 2005 .

RAMALHO, B. L.; MADEIRA, V. de P. C. A pós-graduação em educação no Norte e Nordeste: desafios, avanços e perspectivas. Revista Brasileira de Educação, Rio de Janeiro, n. 30, p. 70-81, 2005.

GIMENO SACRISTÁN, J. Saberes e incertezas sobre o currículo. Porto Alegre: Penso, 2013.

SAYÃO, D. T. Corpo e movimento: notas para problematizar algumas questões relacionadas à Educação Infantil e à Educação Física. Revista Brasileira de Ciências e Esporte, Campinas, v. 23, n. 2, p. 55-67, 2002.

SANTOS, L. H. S. dos. Pedagogias do corpo: representação, identidade e instâncias de produção. In: SILVA, L. H. da (Org.). Século XXI: Qual conhecimento? Qual currículo? Petrópolis: Ed. Vozes, 1999. p. 194-211.

SILVA. T. T. Apresentação. In: GOODSON, I.F. Currículo: teoria e história. Petrópolis: Vozes, 2012. p. 7-13.

SOARES, C. L. Corpo, conhecimento e educação. In: SOARES, C. L. (Org.). Corpo e história. Campinas, SP: Autores Associados. 2001. p. 109-129.

SOARES, C. L.; FRAGA, A. B. Pedagogia dos corpos retos: das morfologias disformes às carnes humanas alinhadas. Pro-Posições, Campinas, v. 14, n. 2, p. 77-90, 2003. 
VAZ, A. F. Aspectos, contradições e mal-entendidos da educação do corpo e a infância. Motrivivência, Florianópolis, ano XII, n.19, p. 135-143, 2002.

Recebido em: 04/03/2018

Revisado em: 10/11/2018

Aprovado em: 27/12/2018

Endereço para correspondência:

marcia.simao@gmail.com

Márcia Buss-Simão

Universidade Federal de Santa Catarina, Centro de Educação - CED.

UFSC - Universidade Federal de Santa Catarina

Trindade

88040900 - Florianópolis, SC - Brasil 